\title{
Gdansk Hybrid Heartlink Programme (GHHP) - we need to share the experience with miniinvasive hybrid procedures in borderline babies
}

\author{
Ireneusz Haponiuk, Maciej Chojnicki, Radoslaw Jaworski, Mariusz Steffens, Aneta Szofer-Sendrowska, Jacek Juscinski \\ Department of Paediatric Cardiac Surgery, Mikolaj Kopernik Pomeranian Centre of Traumatology, Gdansk, Poland
}

Videosurgery Miniinv 2013; 8 (3): 238-240

DOI: $10.5114 /$ wiitm.2011.34210

\begin{abstract}
The Gdansk Hybrid Heartlink Programme follows the concept of the hybrid procedures that combine the advantages of classic surgical operations with intraoperative cardiology interventions. With time and our growing experience, we found that hybrid methods were especially beneficial in cardiac emergencies in borderline babies, who would not meet separate criteria either for surgery or for cardiac interventions. Hybrid strategies appeared safe and effective for patients with anatomical variants unsuitable either for classic surgical or interventional procedures introduced alone. Therefore hybrid treatment seems to be a reasonable alternative mainly because of diminished risk of fatal complications. The success of a hybrid programme is possible in institutions that improve the spirit of cooperation between cardiac surgeons and interventional cardiologists, aimed at the common benefit of borderline patients.
\end{abstract}

Key words: miniinvasive hybrid procedures, congenital heart defects, paediatric cardiac surgery.

The Department of Paediatric Cardiac Surgery in Gdansk was established in 2008 as a new cardiac centre for children with congenital heart defects in northern Poland [1]. Since then a total of 400 cardiopulmonary bypass (CPB) procedures have been performed, while 600 patients have been operated on without CPB. The 'offer' of the Institution was supplemented with the introduction of new hybrid cardiac procedures - begun in 2009 and named the Gdansk Hybrid Heartlink Programme (GHHP). We followed the concept of the hybrid procedures that combined the advantages of a classic surgical operations with intraoperative cardiology interventions. With time and our growing experience we found that hybrid methods, with their great advantages of simultaneous surgical and interventional techniques, were especially beneficial in cardiac emer- gencies in borderline babies, who would not meet separate criteria for either surgery or cardiac interventions.

Hybrid procedures allow one to avoid the adverse effects of a surgical procedure with cardiopulmonary bypass, and the complications of peripheral vascular access, which is twice as important in haemodynamically unstable, and very small babies. The first hybrid procedure was successfully performed in Gdansk in the second half of 2009, immediately after professional training at the Nationwide Children's Hospital in Columbus, Ohio, USA, under the supervision of Dr Mark Galantowicz and Dr John Cheatham.

From the beginning of the programme, the most popular hybrid procedure in Gdansk was perventricular closure of muscular ventricular septal defect (mVSD). We performed 12 successful hybrid mVSD

Address for correspondence:

Radoslaw Jaworski MD, PhD, Department of Paediatric Cardiac Surgery, Mikolaj Kopernik Pomeranian Centre of Traumatology,

1-6 Nowe Ogrody St, 80-803 Gdansk, Poland, phone: +48 5876408 25, e-mail: radicis@go2.pl 
operations in small infants (average body mass less than $6 \mathrm{~kg}$ ), with either a primary or staged approach after primary PA banding $[2,3]$. The technique itself using the Amplatzer VSD Occluder (AGA Med. Corp., USA) and Amplatzer Duct Occluder II (AGA Med. Corp., USA) and their advantages were described in our previous reports [4]. All patients had a benefit without major complications, and remain under careful outpatient control with median follow-up time of 19 months. The observed advantages of the hybrid approach were: direct closure of the defect under simultaneous imaging control, smaller risk of haemodynamic compromise, diminished risk of failed device closure complications, as well as the described option of concomitant defects correction [2].

Hypoplastic left heart syndrome (HLHS) is a congenital defect in which both the left ventricle and the aorta are underdeveloped, which results in a critical impairment in cardiac output. Babies with complex forms of single ventricle (SV) similar to patients with HLHS usually undergo a series of classic palliative procedures as well, aimed at separation of the systemic circulation from pulmonary blood supply. The alternative hybrid approach to palliation of suboptimal single ventricle and HLHS newborns utilizes separate pulmonary artery bands, fluoroscopy controlled stent placement in the patent arterial duct (PDA), and atrial septostomy. Following our initial experience, the hybrid single ventricle approach has emerged as an alternative treatment strategy that could be a reasonable option for a selective group of borderline patients with contraindications for classic surgical treatment. We successfully followed the concept of a hybrid palliative treatment in selective babies with critical congenital diaphragmatic hernia, who underwent right pulmonary artery banding with direct PDA stent implantation. The hybrid cardiovascular procedure was intended for temporary support of the recovery of underdeveloped left ventricle in the settings of left lung hypoplasia and critical heart failure.

A novel approach used in the GHHP was percutaneous stent implantation for primary palliation and the staged treatment of critical aortic coarctation in newborns with severe multiorgan failure. It was successfully done in a critically ill newborn with general contraindications for any surgery on the second day of life - as a bridge procedure to postpone surgical aortic arch repair to early infancy. The final surgery is technically more feasible in young infants, in whom primary neonatal correction might have been either too risky, or clearly contraindicated for a variety of general reasons [5].

What seems to be twice as interesting, hybrid strategies appeared effective in emergency treatment of complications after failed percutaneous cardiac interventions. Our hybrid team performed an emergency patent arterial duct ligation with simultaneous intraoperative miniinvasive catheter removal of a peripherally displaced Amplatzer Duct Occluder II device (AGA Med. Corp., USA). The implant was removed from the left pulmonary artery, using a bioptome and transpulmonary approach (Cook, EU), without cardiopulmonary bypass [6]. This is another argument that modern hybrid strategies combining cardiac surgery with interventional cardiac techniques provide new, less invasive algorithms for different clinical settings.

In conclusion, hybrid procedures are brand new procedures for the treatment of borderline congenital heart defects in children. Hybrid strategies have proved safe and effective for patients with anatomical variants unsuitable for either classic surgical or interventional procedures introduced alone. Therefore hybrid treatment seems to be a reasonable alternative for surgery and transcatheter cardiac interventions in small children, mainly because of diminished risk of fatal complications.

The success of a hybrid programme is possible in institutions that improve the spirit of cooperation between cardiac surgeons and interventional cardiologists, aimed at the common benefit of borderline patients [7]. Therefore we suggest that there is a need to share individual experience to highlight the new strategies in professional literature, and to develop hybrid therapies for the benefit of selected, borderline patients.

\section{Acknowledgments}

We strongly acknowledge the support of Dr Mark Galantowicz and Dr John Cheatham from the Nationwide Children's Hospital in Columbus, Ohio, USA, who gave us fundamental skills and shared their spirit of cooperation, which encouraged us to develop the Gdansk Hybrid Heartlink Programme in the Department of Paediatric Cardiac Surgery in Gdansk, Poland.

\section{References}

1. Haponiuk I, Chojnicki M, Domoslawski M, et al. Nowa kardiochirurgia dziecięca w Gdansku. Kardiochir Torakochi 2008; 5: 224-7. 
2. Haponiuk I, Chojnicki M, Jaworski R, et al. Miniinvasive hybrid closure of multiple muscular ventricular septal defects in a premature infant with novel use of Amplatzer Duct Occluder II a case report. Videosurgery Miniinv 2011; 6: 33-6.

3. Haponiuk I, Chojnicki M, Jaworski R, et al. Delayed closure of multiple muscular ventricular septal defects in an infant after coarctation repair and a hybrid procedure - a case report. Heart Surgery Forum 2011; 14: E67-9.

4. Chojnicki M, Haponiuk I, Jaworski R, et al. Intraoperative imaging of hybrid procedure for muscular ventricular septal defects closure with Amplatzer Duct Occluder II. Kardiol Pol 2011; 69: 1280-1.

5. Sroka M, Haponiuk I, Chojnicki M, Czauderna P. Cardiovascular hybrid procedure in severe congenital diaphragmatic hernia with significant left heart hypoplasia. Eur J Cardiothorac Surg 2012; 42: 185-7.

6. Haponiuk I, Chojnicki M, Jaworski R, et al. Miniinvasive hybrid procedure for device migration after percutaneous closure of persistent arterial duct: a case report. Videosurgery Miniinv 2012; 7: 202-5.

7. Mroczek T, Kusa J, Kordon Z, et al. Hybrid, perventricular closure of muscular ventricular septal defects. Kardiol Pol 2012; 70: 1280-2.

Received: 5.02.2013, accepted: 21.02.2013. 